\title{
Short communication: Prevalence, risk factors, and a field scoring system for udder cleft dermatitis in Dutch dairy herds
}

\author{
R. G. M. Olde Riekerink, ${ }^{*} \ddagger^{1}$ K. van Amersfort, ${ }^{*} \dagger$ O. C. Sampimon, ${ }^{*} \S$ G. A. Hooijer, $\dagger$ and T. J. G. M. Lam ${ }^{*} \dagger$ \\ ${ }^{*}$ GD Animal Health Services, PO Box 9, 7400AA Deventer, the Netherlands \\ †Department of Farm Animal Health, Institute of Ruminant Health Care, Faculty of Veterinary Medicine, Utrecht University, Yalelaan 7 , \\ 3584CL Utrecht, the Netherlands \\ łBayer New Zealand Ltd., PO Box 2825, Auckland 1140, New Zealand \\ §Zoetis, PO Box 81055, 3009 GB Rotterdam, the Netherlands
}

\section{ABSTRACT}

Udder cleft dermatitis (UCD) is a well-known disorder in dairy cows. Veterinary literature about this subject, however, is scarce. The objectives of this study were to define a clinical scoring system for UCD, estimate the within-herd prevalence of UCD, and identify potential risk factors of UCD at cow and herd level. On 20 randomly selected dairy farms in the Netherlands, each lactating cow was photographed from a ventral, lateral, and caudal position. A scoring system with 6 categories of severity of UCD was proposed based on the ventral photographs. Cow measures such as udder width and depth, and front quarter attachment were determined from the lateral and caudal photographs. A questionnaire was conducted on each farm during farm visits. Udder cleft dermatitis, defined as a score 3 or higher, was detected in $5.2 \%$ of the 948 cows involved in this study. Within-herd prevalences of UCD ranged between 0 and $15 \%$ and UCD was found in $16(80 \%)$ of the participating farms. Cows with a deep udder (relative to the hock), large front quarters, and a small angle between udder and abdominal wall were more likely to develop UCD. Production level and use of a footbath were identified as being positively associated with herd-level UCD prevalence. Herd size and average bulk milk somatic cell count did not seem to be associated with UCD prevalence. Because of the small herd sample size, no firm conclusions were drawn on herdlevel risk factors. However, results from this study can be used in designing a future longitudinal UCD study. The prevalences of UCD found in the present study illustrate the current UCD situation in the Netherlands. Our results demonstrate that multiple potential risk factors of UCD could be identified at both the cow and herd level.

Received October 29, 2013.

Accepted March 24, 2014.

${ }^{1}$ Corresponding author: richard.olderiekerink@bayer.com
Key words: udder cleft dermatitis, prevalence, risk factor, classification

\section{Short Communication}

Udder cleft dermatitis (UCD), also known as bovine ulcerative mammary dermatitis or foul udder, is an inflammation of the skin and is most often located between the front quarters and at the transition of the front quarters and the abdominal wall. Characteristic features of UCD are a moist appearance, skin necrosis, and a foul odor, which is caused by opportunistic anaerobic bacteria that colonize beneath the scabs and necrotizing skin (George et al., 2008). In untreated cases, deep lesions can be found (Boyer and Singleton, 1998). Field reports exist of erosion into subcutaneous veins resulting in severe hemorrhage and even death (R. G. M. Olde Riekerink, unpublished data). The deep lesions can also impair animal welfare, milk production, and milk quality, and can lead to premature culling. Necrotic dermatitis of the udder skin of the hindquarters or the skin of the thighs of heifers or young cows (Blowey and Weaver, 2011) is probably not the same as UCD, occurs in anatomically distinct areas, and may have different etiology and risk factors, and is therefore not considered in this study.

Udder cleft dermatitis is a well-known disorder in dairy cows, but is scarcely described in veterinary literature. To date, the etiology and an effective therapy for UCD are unknown. Stamm et al. (2009) suggested that several Treponema phylotypes present in UCD lesions were associated with those cultured from bovine digital dermatitis (BDD). Other authors also identified spirochetes in samples from UCD lesions (Beattie and Taylor, 2000; Evans et al., 2010; Keil et al., 2002; Stamm and Trott, 2006).

Udder cleft dermatitis has been reported before in Scotland (Beattie and Taylor, 2000), the United Kingdom (Boyer and Singleton, 1998), the United States (Keil et al., 2002; Warnick et al., 2002; Stamm et al. 2009), and more recently in Sweden (Persson Waller 
et al., 2014). Reported prevalences were $18 \%$ in the United States (Warnick et al., 2002), 22\% in 1 Scottish farm and $1.4 \%$ in an abattoir survey of 331 culled cows (Beattie and Taylor, 2000), and up to $39 \%$ within herd and $18.5 \%$ average in Sweden (Persson Waller et al., 2014).

The objectives of this study were to define UCD on a clinical score, estimate the prevalence in Dutch dairy farms, and identify potential risk factors at both the cow and herd level.

Farms were randomly selected from a list containing all milk-supplying farms in the Netherlands, using the following inclusion criteria: the predominant breed was Holstein-Friesian, herd size was at least 40 and no more than 120 lactating and nonlactating cows, and cows were housed in freestall barns with sufficient headlock facilities and milk recording. A total of 13,992 dairy herds fit the herd size selection criteria. To enroll 20 farms, 57 randomly selected farms were approached. Nine farms did not meet the inclusion criteria. Twenty-eight were not interested in participating. The 20 participating farms were visited between June and November 2010.

A total of 1,083 lactating cows on each participating farm were photographed from a ventral, lateral, and caudal positions, of which 948 resulted in usable and complete data. Animals were fixed in headlocks during this process. Cow identification cards were clipped on a folding ruler and were photographed with every cow. Ventral photographs were taken using a mirror on a stick and a digital camera attached to the stick. Lateral and caudal photographs were taken as consistently as possible with respect to the craniocaudal line of the cow $\left(90^{\circ}\right.$ respectively $\left.0^{\circ}\right)$. On each farm, a survey was conducted containing questions about herd size, production level, bulk milk SCC, ventilation, alley floor type and cleaning frequency, use of a footbath, presence of BDD, presence of sarcoptic mange (farmer reported), bedding type, bedding replacement frequency, stall cleaning frequency, and the use of lime in the bedding material.

Based on the ventral photographs, 6 categories were proposed: $0=$ no trace of $\mathrm{UCD} ; 1=$ discoloration or moist appearance in the area mediocranial of the front quarters; $2=$ hair loss or skin abrasion; $3=$ closed skin crusts; $4=$ open wound, no skin; and $5=$ open wound and bloody, serous, or purulent exudate (Figure 1). A classification score of 3 or higher was considered positive for UCD. A farm was considered positive if at least 1 animal scored 3 or higher.

Lateral photographs were used to determine the angle between udder and abdominal wall, front quarter size, lower leg size (measured as the distance between os calcaneus and dew claws), and lateral hygiene scores. Caudal photographs were used to determine the ud- der depth (vertical distance between the udder floor and the hock), udder width, udder cleft (strength of median suspensory ligament), distance between the tuber ischiae, and hygiene scores. Relative udder width was calculated as the udder width divided by distance between the tuber ischiae. Additionally, hygiene scores of udders, thighs, and legs were recorded from these photographs (range of 1 to 4: clean to very dirty, respectively; Schreiner and Ruegg, 2002). Photo-editing software was used to measure distances and angles (Adobe Photoshop CS5 extended version 12.0; Adobe Systems Inc., San Jose, CA). The fore udder attachment was measured on lateral view as the angle between the line of the fore udder skin and the line of the abdominal wall on the transition of both. Measures were adjusted using the pixel distance of the photographed folding ruler, after determining for each photograph how many centimeters on the folding ruler corresponded to the number of pixels in the photograph.

Statistical analyses were done using Stata 13 (Stata/ IC 13.0 for Windows; Stata Corp., College Station, TX). Independent variables were the potential risk factors and the dependent variable was presence in a cow (cow-level analyses) or proportion of cows with clinical UCD in a herd (herd-level analyses). Univariable logistic regression analyses were used to determine the association between the potential risk factors at cow level and the presence of UCD. Regression analyses were used to determine the association between the potential risk factors at herd level and the presence of UCD. For both cow- and herd-level analyses, a significance level of $P \leq 0.05$ was used.

In total, 1,106 lactating cows were presented for the study, but because of aggressive and unsafe behavior, 23 were not photographed. From the 1,083 that were photographed, 135 had insufficient photo quality (dirt, blurring, or light) and were excluded from data analyses. In the remaining 948 lactating cows, 49 (5.2\%) cows were considered positive for UCD (Table 1). Herd-level prevalences ranged from 0 to $15 \%$. Udder cleft dermatitis was found in $80 \%$ (95\% binomial CI: 56-94\%) of the herds.

Only lactating cows were included in analyses of potential risk factors for UCD at the cow level. Out of 12 examined cow-level potential risk factors, 3 were associated with clinical UCD (Table 2). Small angles (smallest quartile was between 49 and $97^{\circ}$ ) between udder and abdominal wall increased the odds of clinical UCD $(P=0.02)$ as well as larger front quarter sizes $(P$ $<0.01)$ and deeper udders $(P=0.01$; Table 2$)$.

Out of the 10 tested potential risk factors at the herd level, 2 seemed to be positively associated with the prevalence of UCD in the herd (Table 3), herd mean production level $(P=0.04)$, and presence of footbaths 
Table 1. Udder cleft dermatitis (UCD) severity scores in 1,106 dairy cows

\begin{tabular}{lcc}
\hline $\begin{array}{l}\text { Category } \\
\text { of UCD }\end{array}$ & Frequency & $\%$ \\
\hline 0 & 662 & 69.8 \\
1 & 221 & 23.3 \\
2 & 16 & 1.7 \\
3 & 33 & 3.5 \\
4 & 12 & 1.3 \\
5 & 4 & 0.4 \\
Subtotal & 948 & 100 \\
Not photographed & 23 & - \\
Not interpretable & 135 & - \\
Total & 1,106 & - \\
\hline
\end{tabular}

$(P=0.04)$. Half of the enrolled farms reported a yearly milk production of $9,000 \mathrm{~kg}$ per cow or more and had an average UCD prevalence of $7.7 \%$ (ranging from 2.4 to $14.6 \%$ ), whereas the lower-production farms had an average prevalence of $2.5 \%$, ranging from 0 to $11.6 \%$. Similarly, on farms where a foot bath was present (n $=13$ ) the mean UCD prevalence was $6.6 \%$, ranging from 1.6 to 14.6, and where no foot bath was present, the UCD prevalence ranged from 0 to $12 \%$, averaging $2.3 \%$. The variable type of floor and ventilation system were omitted from the analysis due to lack of variation within this variable (19 out of 20 farms had slatted floors) or too much unclassifiable variation.

\begin{tabular}{|c|c|c|c|c|c|}
\hline Category & Description & Picture example & Category & Description & Picture example \\
\hline 1 & $\begin{array}{l}\text { Color shift. } \\
\text { Between the front } \\
\text { quarters and at the } \\
\text { transition of the } \\
\text { front quarters and } \\
\text { the abdominal } \\
\text { wall, an explicit } \\
\text { color shift is } \\
\text { visible. The change } \\
\text { of color usually } \\
\text { has a reddish } \\
\text { appearance and } \\
\text { seems darker than } \\
\text { the rest of the udder }\end{array}$ & & 4 & $\begin{array}{l}\text { Open wounds. The } \\
\text { degree of wound } \\
\text { formation can } \\
\text { differ within this } \\
\text { category }\end{array}$ & \\
\hline 2 & $\begin{array}{l}\text { Alopecia, skin } \\
\text { with bald patches, } \\
\text { scales, scrapes, } \\
\text { and / or scars }\end{array}$ & & 5 & $\begin{array}{l}\text { Open wounds with } \\
\text { exudate such as } \\
\text { pus and / or blood }\end{array}$ & \\
\hline
\end{tabular}

Figure 1. Picture examples for each category of clinical udder cleft dermatitis score. Color version available in the online PDF. 
Table 2. Univariate analysis of risk factors for udder cleft dermatitis (UCD) at the cow level

\begin{tabular}{|c|c|c|c|c|}
\hline Measured variable & Mean (SD) & $\begin{array}{l}\text { Range, } \\
\text { minimum } \\
\text { to maximum }\end{array}$ & $\begin{array}{l}\text { Associated with } \\
\text { higher probability } \\
\text { of UCD }\end{array}$ & $P$-value \\
\hline Angle between udder and abdominal wall $\left(^{\circ}\right)$ & $108(19.3)$ & 49 to 164 & Smaller angle & 0.02 \\
\hline Udder depth, relative to hock $(\mathrm{cm})$ & $5.1(5.5)$ & -13 to 21 & Deeper & 0.01 \\
\hline Udder width $(\mathrm{cm})$ & $17.4(3.2)$ & 8 to 27 & - & 0.59 \\
\hline Distance between tuber ischiae $(\mathrm{cm})$ & $21.0(3.0)$ & 13 to 35 & - & 0.28 \\
\hline Distance between os calcaneus and dew claws $(\mathrm{cm})$ & $32.2(4.5)$ & 16 to 44 & - & 0.48 \\
\hline Hygiene score udder lateral view ${ }^{1}$ & 1.4 & - & - & 0.51 \\
\hline Hygiene score udder posterior view ${ }^{1}$ & 2.4 & - & - & 0.38 \\
\hline Hygiene score thighs ${ }^{1}$ & 2.1 & - & - & 0.54 \\
\hline Hygiene score lower legs ${ }^{1}$ & 3.0 & - & - & 0.35 \\
\hline
\end{tabular}

${ }^{1}$ Range of 1 to 4: clean to very dirty, respectively (Schreiner and Ruegg, 2002).

We found, with $80 \%$ (95\% binomial CI: 56-94\%) of randomly selected herds having affected cows, that UCD is highly prevalent among dairy herds in the Netherlands. Some variation in prevalence existed within herds, ranging from 0 to $15 \%$ of cows. Udder cleft dermatitis was known as a problem in dairy herds, but it was found to be more prevalent than expected at the herd level, although with low numbers of affected cows per herd. Some selection bias might have occurred during the enrollment of farms. Farmers that knowingly had UCD on their farm might have been more inclined to participate.

Variation between herds was expected to be related to management factors, such as cleaning frequency of alley floors and stalls, and to farm characteristics, such as herd size and average production level. To study herd-level factors influencing UCD, a much larger study size is needed. The purpose of the current study was to develop a standard scoring system for UCD and to identify potential risk factors that can be included or excluded in follow-up work. To make that practically possible, an easier diagnostic method to monitor UCD prevalence might need to be developed as well.
Early stages of UCD may be the red irritated areas, as seen in category 1 and 2 cows, which later on develop into the typical UCD wounds and lesions as seen in categories 3,4 , and 5 . It is also possible that the category 2 cows with scars or bald spots have had typical UCD lesions in the past that have healed. Because the development of UCD lesions is not fully understood, UCD prevalence may be underestimated in this study.

Our study showed, not surprisingly, that UCD can be observed more frequently in cows with a small angle between udder and abdominal wall. Additionally, a large front quarter was found to be a risk factor for UCD. These factors may create a good microclimate for the causative microorganisms to colonize, resulting in UCD, as has been described for skin fold dermatitis in dogs, which is caused by friction between skin folds (Ihrke, 1987; Medleau and Hnilica, 2006). Contrary to our expectations, however, no association existed between the strength of the median suspensory ligament, causing a deep groove between left and right quarters, and the prevalence of UCD. Finally, lactation stage got our attention. A strong correlation between UCD and the dry period was found (data not presented). Given

Table 3. Potential risk factors for udder cleft dermatitis at the herd level

\begin{tabular}{|c|c|c|c|}
\hline Measured variable & $\begin{array}{l}\text { Direction of } \\
\text { association }\end{array}$ & Number of farms & $P$-value \\
\hline Herd size & - & - & 0.71 \\
\hline Mean bulk milk SCC & - & - & 0.32 \\
\hline Alley floor type & Not assessable & - & - \\
\hline High frequency of the alley scraping & $\geq 8$ times $/ \mathrm{d}$ & 8 & 0.27 \\
\hline Presence of sarcoptic mange in lactating cows, farmer's report & Yes/no & 2 & 0.69 \\
\hline Type of bedding & Categorical & - & 0.38 \\
\hline Use of lime in stalls & Yes/no & 12 & 0.91 \\
\hline
\end{tabular}


the low number of dry cows $(\mathrm{n}=30)$ in our study, this was not further elaborated. As stated before, for more detailed information on the development of UCD, a longitudinal study would be needed.

Presumptive evidence was found for a correlation between UCD and herd mean production level and use of a footbath (Table 3). Higher prevalences of UCD seem to be related to production level, as was earlier described by Beattie and Taylor (2000) and demonstrated at the cow level by Persson Waller et al. (2014). We hypothesized that high milk production is correlated with large and possibly warm udders, which we thought were factors that could influence the development of UCD. The other herd-level risk factor we found that might be of importance is the presence of a footbath for the lactating cows, being associated with a morethan-double prevalence of UCD. The use of a footbath might be a proxy for high risk for BDD on the farm, as the latter is considered to be caused by a group of treponemes and similar organisms have been found in UCD lesions (Evans et al., 2010). Warnick et al. (2002), however, concluded that UCD and BDD were negatively associated. It may be that although BDD may be well controlled by foot bathing, the risk of infection for UCD and its prevalence might remain high.

A clinical (0 to 5 scale) scoring system for UCD was proposed and, based on that, UCD was found in $5.2 \%$ of 948 examined cows in 20 randomly selected herds, with herd-level prevalences ranging between 0 and $15 \%$. Udder cleft dermatitis was detected in $16(80 \%)$ of the participating herds. A positive association was found between UCD and udder depth (relative to the hock), front quarter size, and a small angle between udder and abdominal wall, all related to the shape of the udder. Due to the size of the study, herd-level risk factors were only indicative. In this study, mean herd-level production and use of a footbath were associated with the UCD prevalence in the herd.

\section{ACKNOWLEDGMENTS}

This study was funded by the Dutch Dairy Board (Zoetermeer, the Netherlands). We thank the farmers who welcomed us on their farms and took the time and effort to assist us with our work during the visits.

\section{REFERENCES}

Beattie, K. G., and D. J. Taylor. 2000. An investigation into intertrigo (necrotic dermatitis or 'foul udder') in dairy cows. Cattle Pract. $8: 377-380$.

Blowey, R. W., and A. D. Weaver. 2011. Udder and teat disorders. Pages 217-218 in A Color Atlas of Diseases and Disorders of Cattle. 3rd ed. Elsevier Ltd., Edinburgh, UK.

Boyer, P., and G. Singleton. 1998. Digital dermatitis superfoul and severe necrotic dermatitis of the udder in dairy cows. Vet. Rec. 142:147-148.

Evans, N. J., D. Timofte, S. D. Carter, J. M. Brown, R. Scholey, D. H. Read, and R. W. Blowey. 2010. Association of treponemes with bovine ulcerative mammary dermatitis. Vet. Rec. 166:532-533.

George, L. W., T. J. Divers, N. Ducharme, and F. Welcome. 2008. Diseases of the teats and udder. Pages 331-333 in Rebhun's Diseases of Dairy Cattle. T. J. Divers and S. F. Peek, ed., Elsevier Inc., St. Louis, MO.

Ihrke, P. J. 1987. An overview of bacterial skin disease in the dog. Br. Vet. J. 143:112-118.

Keil, D. J., D. Read, T. F. Sturgis, and C. R. Bockenstedt. 2002. Isolation of a (papillomatous) digital dermatitis-associated Treponema spp. from bovine udder lesions. Abstract no. 14 in Proc. 83rd Annu. Mtg. Conf. Res. Workers Anim. Dis. St. Louis, MO.

Medleau, L., and K. A. Hnilica. 2006. Chapter 2: Diagnostic techniques. Pages 26-28 in Small Animal Dermatology: A Color Atlas and Therapeutic Guide. Saunders Elsevier, St. Louis, MO.

Persson Waller, K., M. Bengtsson, and A.-K. Nyman. 2014. Prevalence and risk factors for udder cleft dermatitis in dairy cattle. J. Dairy Sci. 97:310-318.

Schreiner, D. A., and P. L. Ruegg. 2002. Effects of tail docking on milk quality and cow cleanliness. J. Dairy Sci. 85:2503-2511.

Stamm, L. V., and D. J. Trott. 2006. Treponema and bovine skin disease: Papillomatous digital dermatitis and ulcerative mammary dermatitis. Pages 403-420 in Pathogenic Treponema: Molecular and Cellular Biology. J. D. Radolf and S. A. Lukehart, ed. Caister Academic Press, Norfolk, UK.

Stamm, L. V., R. L. Walker, and D. H. Read. 2009. Genetic diversity of bovine ulcerative mammary dermatitis-associated Treponema. Vet. Microbiol. 136:192-196.

Warnick, L. D., D. Nydam, A. Maciel, C. L. Guard, and S. E. Wade. 2002. Udder cleft dermatitis and sarcoptic mange in a dairy herd. J. Am. Vet. Med. Assoc. 221:273-276. 